\title{
Associations between motives for dish choice during home-meal preparation and diet quality in French adults: findings from the NutriNet-Santé study
}

\author{
Pauline Ducrot ${ }^{1}{ }^{*}$, Caroline Méjean ${ }^{1}$, ${\text { Philippine } \text { Fassier }^{1} \text {, Benjamin Allès }}^{1}$, Serge Hercberg ${ }^{1,2}$ and \\ Sandrine Péneau ${ }^{1}$ \\ ${ }^{1}$ Equipe de Recherche en Epidémiologie Nutritionnelle, Centre de Recherche en Epidémiologie et Statistiques, National Institute \\ for Health and Medical Research (INSERM ,U1153), National Institute for Agricultural Research (INRA, U1125), National \\ Conservatory for Arts and Crafts (CNAM), COMUE Sorbonne Paris Cité, Université Paris 13, Bobigny F-93017, France \\ ${ }^{2}$ Department of Public Health, Hôpital Avicenne, Bobigny Cedex F-93017, France
}

(Submitted 18 July 2016 - Final revision received 17 February 2017 - Accepted 26 February 2017 - First published online 10 April 2017)

\section{Abstract}

A number of motives such as constraints or pleasure have been suggested to influence dish choices during home-meal preparation. However, no study has evaluated how the importance conferred to these motives potentially influence diet quality. The present study aims at investigating the difference in diet quality according to the importance attached by individuals to various dish choice motives. The importance of twenty-seven criteria related to dish choices on weekdays was evaluated among 48010 French adults from the NutriNet-Santé study. ANCOVA and logistic regression models, adjusted for sociodemographic and lifestyle factors, were used to evaluate the association between the importance attached to dish choice motives (yes $v$. no) and energy and food group intakes, as well as adherence to French nutritional guidelines (modified Programme National Nutrition Santé-Guideline Score (mPNNS-GS)). A higher adherence to nutritional guidelines was observed in individuals attaching importance to a healthy diet (mPNNS-GS score 7.87 (sD 0.09) $v .7 .39$ (sD 0.09)) and specific diets (mPNNS-GS score 7.73 (SD 0.09) $v .7 .53$ (SD 0.09)), compared with those who attached little/no importance (all $P<0.0001$ ). These individuals also exhibited higher intakes of fruits and vegetables, but a lower consumption of meat, milk and cheese, sugary products and convenience foods compared with their respective counterparts (all $P<0.0001$ ). For other motives, that is, constraints, pleasure and organisation, only small differences were observed. The main difference in diet quality was related to the importance placed on a bealthy diet. Although a causal link should be demonstrated, our findings suggested that strategies aiming at enabling people to take into account diet quality during home-meal preparation might be effective levers to promote healthy eating.

Key words: Dish choices: Home-meal preparation: Diet quality: Cross-sectional studies

Over the past decades, lifestyle and food offer changes have led to an evolution of cooking practices in Western societies ${ }^{(1)}$. Overall, less time is spent in home-meal preparation ${ }^{(2,3)}$ and an increasing part of the diet is provided by away-from-home sources (i.e. ready meals, eating out) ${ }^{(4-6)}$.

A potential influence of cooking practices on the diet quality has been suggested in a few studies ${ }^{(7-12)}$. In particular, a greater frequency of food preparation in US young adults and adolescents has been associated with a better overall diet quality, including better compliance with nutritional guidelines ${ }^{(8)}$, less frequent consumption of fast food ${ }^{(8)}$, lower intake of fat and higher intakes of fruits and vegetables, fibre, folate and vitamin $A^{(9)}$. Similarly, in US young adults, a greater frequency of food preparation predicted better diet quality 5 years later, including higher intakes of fruits, vegetables and dark green/ orange vegetables, and lower consumption of sugar-sweetened beverages and fast-food ${ }^{(10)}$. The amount of time devoted to food preparation in US adults has also been positively associated with indicators of higher diet quality including more frequent intake of vegetables, salads, fruits and fruit juices ${ }^{(11)}$. In addition, in Switzerland, cooking skills were shown to be positively associated with vegetable consumption and negatively with convenience food intakes ${ }^{(7)}$; furthermore, a communitybased intervention in Scotland showed that improving cooking skills increases fruit consumption ${ }^{(12)}$.

In addition to cooking barriers such as poor cooking skills ${ }^{(7,13,14)}$ and time scarcity ${ }^{(2,15-19)}$, which have been mainly studied in the literature, a number of additional motives could potentially influence dish choice and therefore the dietary quality of the meals prepared. If food choice motives during grocery shopping have been largely described in the literature $^{(20-25)}$, to our knowledge, only two have focused on food choices during home-meal preparation. A previous mixedmethods study, evaluating among fifty Dutch adults the motives

Abbreviation: $\mathrm{CU}$, consumption units.

* Corresponding author: P. Ducrot, fax +33 1483889 31, email p.ducrot@eren.smbh.univ-paris13.fr 
for choosing different meal solutions including homemade meals and different ready meals (e.g. frozen pizza, chilled hotpot), highlighted that the choice was the result of the balance between a number of criteria including health, convenience, taste, pleasure or price ${ }^{(26)}$. Furthermore, the latter study concluded that the prioritisation of one motive over the other could lead to different meal solutions ${ }^{(26)}$ in which nutritional quality potentially differs. More recently, a quantitative study performed in the NutriNetSanté cohort study supported that dish choices are governed by various motives including healthy diet, constraints, pleasure, specific diets and organisation ${ }^{(27)}$. Although the Dutch study suggested that motives governing dish choice are likely to influence the diet quality ${ }^{(26)}$, no study so far has investigated the corresponding association with various dish choice motives. Assessing which motivations during home-meal preparation are correlated with a healthier diet appears to be of importance for guiding interventions to improve home eating habits.

The aim of the present study was therefore to evaluate the difference in diet quality according to the importance attached by individuals to various dish choice motives for home-meal preparation and adherence to nutritional guidelines, as well as energy and food intakes.

\section{Methods \\ Study population}

NutriNet-Santé (https://www.etude-nutrinet-sante.fr) is an ongoing web-based prospective observational cohort study launched in France in May 2009 with a scheduled follow-up of 10 years. It aims to investigate the relationship between nutrition and chronic disease risk, as well as the determinants of dietary behaviour and nutritional status. The study was implemented in the general French population (Internet-using adult volunteers, age $\geq 18$ years). The rationale, design and methodology of the study have been fully described elsewhere ${ }^{(28)}$. In brief, to be included in the study, participants complete a baseline set of self-administered, web-based questionnaires assessing dietary intake, physical activity, anthropometric characteristics, lifestyle, socioeconomic conditions and health status. As part of the follow-up, participants are requested to complete the same set of questionnaires every year. Moreover, each month, participants are invited by email to fill in optional questionnaires related to dietary intakes, determinants of eating behaviours, nutritional and health status. This study is conducted in accordance with the Declaration of Helsinki, and all procedures were approved by the Institutional Review Board of the French National Institute for Health and Medical Research (IRB Inserm no. 0000388FW A00005831) and the Commission Nationale de l'Informatique et des Libertés (CNIL no. 908450 and no. 909216). All participants provided informed consent with an electronic signature. This study is registered in EudraCT (n2013-000929-31).

\section{Data collection}

Dish choice questionnaire. Data concerning dish choices were collected in September 2013 via an optional questionnaire, available for 6 months on the web platform. Information as to whether the participant was involved in the choice of dishes was firstly collected (never, sometimes, often, always) and participants who responded 'never' were exempted from answering the rest of the questionnaire. The questionnaire assessing determinants of dish choices was generated based on existing literature and the expertise of nutritionists, epidemiologists, sociologists and sensory specialists. The questionnaire included twenty-seven items on dish choice motives including commonly recognised factors such as preferences, eating habits, cooking practices, health, constraints related to time and food availability. Participants were asked the following question: 'When choosing the dishes you are going to cook, how important are the following criteria?' (in French: 'Quelle importance donnez-vous aux critères suivants lorsque vous choisissez le plat que vous allez préparer?'). The responses were rated on a five-point Likert scale ranging from 1 (not important at all) to 5 (very important), with each point on the scale represented by a word anchor. Information about dish choice motives was collected for weekdays and weekends separately. In addition, general information on cooking practices was self-reported by participants for both weekdays and weekends that is, time spent in meal preparation $(<15,15-30,30-45,45-60,>60 \mathrm{~min})$, cooking skills (low, medium, high) and cooking enjoyment (yes, no). The full questionnaire is available elsewhere ${ }^{(27)}$.

Sociodemographic, economic and lifestyle characteristics. At baseline and annually thereafter, participants in the NutriNetSanté study were asked to provide sociodemographic data. For each participant, we used the data collected closest to the date at which the questionnaire on dish choice motives was filled in.

The variables used in the present study were the following: sex (men, women), age (18-29, 30-49, 50-64, $\geq 65$ years), educational level (up to secondary school, some college or university degree), family status (living alone without children, living with a partner without children, living alone with at least one child, living with a partner with at least one child), and monthly income (<1200, 1200-1799, 1800-2699, $\geq 2700$ euros per consumption unit (CU)). Monthly household income was calculated per $\mathrm{CU}$, where $1 \mathrm{CU}$ is attributed to the first adult in the household, $0.5 \mathrm{CU}$ for other individuals aged $\geq 14$ years, and $0 \cdot 3 \mathrm{CU}$ for children $<14$ years, following the national statistics methodology and guidelines ${ }^{(29)}$. Physical activity (low, moderate, high) was assessed using a short form of the French version of the International Physical Activity questionnaire ${ }^{(30)}$. The weekly energy expenditure expressed in metabolic equivalent task min/week was estimated, and three scores of physical activity were constituted (i.e. low $(<30 \mathrm{~min} / \mathrm{d})$, moderate $(30-59 \mathrm{~min} / \mathrm{d})$ and high $(\geq 60 \mathrm{~min} / \mathrm{d})$ ) according to the French guidelines for physical activity ${ }^{(30)}$.

Dietary intake assessment. Dietary data were collected using at least three web-based $24 \mathrm{~h}$ dietary records randomly assigned over a 2-week period, including 1 weekend day and 2 weekdays. First, the participant reported all foods and beverages consumed at each eating occasion. Next, the participant estimated portion sizes for each reported food and beverage according to standard measurements or using photographs available via the interactive interface, taken from a validated picture booklet ${ }^{(31)}$. The weekly consumption of fish and seafood was assessed by a specific frequency question as infrequently consumed food. 
For each participant, daily mean food consumption was calculated from the three $24 \mathrm{~h}$ records, weighted for the type of day (weekday or weekend day). Energy and food group intakes were calculated using the NutriNet-Santé composition table including more than 2000 foods $^{(32)}$. Over-consumption was identified at both food and food group levels, using the food intake threshold defined by dietitians and nutritionists. According to the differences observed, different corrections were applied when possible, or the dietary record was deleted. Identification of under-reporting participants was based on the method developed by Black $^{(15)}$. Participants detected as under-reporters were excluded from the analysis.

Adherence to nutritional guidelines was assessed using the Programme National Nutrition Santé-Guideline Score (PNNS-GS). The fifteen-point PNNS-GS is a validated $a$ priori score reflecting adherence to the official French nutritional guidelines, which has been extensively described elsewhere ${ }^{(33)}$. Details on computation of this score are in the online Supplementary Table S1. In brief, it includes thirteen components: eight refer to food-serving recommendations (fruit and vegetables; starchy foods; whole-grain products; dairy products; meat, eggs and fish; fish and seafood; vegetable fat; water $v$. soda), four refer to moderation in consumption (added fat, salt, sweets, alcohol) and one component pertains to physical activity $^{(33,34)}$. Points are deducted for over-consumption of salt $(>12 \mathrm{~g} / \mathrm{d})$, added sugars $(>17.5 \%$ of energy intake) or when energy intake exceeds the needed energy level by $>5 \%$. Each component cut-off was that of the threshold defined by the PNNS public health objectives when available, ${ }^{(34)}$ otherwise they were established according to the French $\mathrm{RDA}^{(35)}$. For the present analysis, we computed a modified version of the PNNS-GS (modified Programme National Nutrition Santé-Guideline Score (mPNNS-GS)) which did not include the physical activity component. Therefore, the maximum score was $13 \cdot 5$.

Food groups included in the study were the following: fruits, vegetables, fish (including seafood and processed seafood), meat (including cooked ham and offal), eggs, milk, cheese, starchy foods (including potato, legumes, pasta, rice, other cereals, flour and whole-grain forms) with a specific focus on legumes and whole-grain starchy foods (including whole-grain pasta, rice, other cereals and flour), added fats (including oil, butter, margarine and vinaigrette), convenience food (e.g. pizzas, burgers, salted pies, sandwiches and fried meals), and sugary products (e.g. cakes, biscuits, sugars, honey, jam and chocolate).

\section{Statistical analysis}

We excluded from the analyses participants who reported never being involved in dish choices in the household and those who provided less than three $24 \mathrm{~h}$ dietary records since their inclusion in the study (i.e. completed between May 2009 and December 2014).

Sociodemographic and cooking practice characteristics of included and excluded participants were compared using $\chi^{2}$ tests. $\chi^{2}$ Tests were also used to compare participants' characteristic across importance given to dish choice motives.

Dish choice motives were identified for weekdays and weekends separately using exploratory factor analyses, fully described elsewhere ${ }^{(27)}$. In brief, as items are represented by ordinal variables, we used the unweighted least squares estimation method based on polychoric correlations ${ }^{(36)}$. The number of 'meaningful' factors to be retained was determined using common methods (i.e. Kaiser criterion ${ }^{(37)}$, scree test ${ }^{(38)}$, proportion of variance accounted for $\left.{ }^{(37)}\right)$. An item was considered to load onto a given factor if factor loading was $\geq 0 \cdot 40$ for that factor and $<0.40$ for the other factors ${ }^{(36)}$. Items having non-negligible loading $(>0 \cdot 30)$ for several factors were removed from further analysis. Internal consistency was evaluated using ordinal $\alpha$-coefficients and reliability was considered acceptable if the coefficient exceeded the threshold of $0 \cdot 60-0 \cdot 70^{(39)}$. Scores on each of the factors drawn in the exploratory factor analysis were computed by averaging unweighted ratings for individual items. Scores could therefore range from 1 to 5 . Mixed models for repeated data were used to assess differences between the levels of importance attached to each factor. Crude and adjusted (i.e. sex, age, educational level, monthly income, physical activity and family status) models were performed. Tukey's post hoc tests were used to evaluate pairwise differences.

In order to compare diet quality according to the importance attached (yes $v$. no) to the different dish choice motive factors, the latter factors (ranging from 1 to 5 ) were recoded as binary variables: important (average score $\geq 4$ ) and not important (average score $<4$ ). This threshold was selected on the basis of the initial item scales labelling: 4 corresponding to 'important' and 5 to 'very important'. Sensitivity analyses using thresholds of 3 and 3.5 were also performed. As similar associations were observed in both contexts (i.e. weekdays, weekends) and because weekdays represent a larger part of the diet, only results for this context were presented.

ANOVA was used to evaluate the associations between the importance attached to dish choice motives (yes $v$. no) and energy intakes, whereas ANCOVA were used to evaluate the associations with mPNNS-GS and food groups that exhibited normal distribution. For food groups that did not exhibit normal distribution (i.e. eggs, legumes, whole-grain starchy foods and convenience foods), mainly because of a high proportion of nonconsumers, a binary variable (consumer/non-consumer) was created and a logistic regression analysis was performed. All models were adjusted for sex, age, educational level, monthly income, physical activity, family status, energy (except for the model with energy as a dependent variable) and corresponding dish choice motives (e.g. the healthy diet model was adjusted for the four other dish choice motives) in order to control the potential effect of one dish choice motive factor on another.

For each food group, interactions between dish choice motives and different sociodemographic variables (i.e. sex, age, monthly income and educational level) were tested. However, overall, no significant effect was observed.

Given the large size of our sample, significant differences were observed for most subgroups, even if some of these were relatively small. We therefore defined a threshold of $5 \%$ as meaningful nutritional differences and discussed only the dietary differences above this threshold. In addition, $P$ values were adjusted for multiple testing using the Holm-Bonferroni method.

Missing covariate data were imputed using the multiple imputation method ${ }^{(40)}$. 
All tests of significance were two-sided, and $P<0.05$ was considered significant. Statistical analyses were performed with SAS software (version 9.3; SAS Institute Inc.)

\section{Results}

From the initial sample of 53025 individuals who answered the questionnaire about dish choice, an exploratory factor analysis was performed on the 50915 individuals who had completed data for the weekday context. Analyses showed a five-factor solution $^{(27)}$ (Table 1). Results of the exploratory factor analysis and factor components have been fully described in a previous $\operatorname{article}^{(27)}$. In brief, the first factor consisted of five items corresponding to bealthy eating motives (e.g. use of seasonal products, nutritional balance of the meal, my eating habits). The second factor included six items, all referring to constraints (e.g. time available for cooking, cooking skills, my state of fatigue). The third factor comprised five items referring to pleasure (e.g. my preferences, originality of the dish, recipes I come across). The fourth factor consisted of three items related to specific diets (i.e. diet for health status, diet to lose weight, diet for personal convictions). Finally, the fifth factor included three items concerning meal organisation (i.e. what I planned to eat, the dish can be prepared beforehand, the dish can be prepared in large quantities).

The importance attached to each of the factors differed significantly $(P<0.0001$ for all paired comparisons), in crude and adjusted models.

From this initial sample of 53025 individuals, 2110 participants reported never being involved in dish choice and were therefore not asked to complete the questionnaire. In addition, we excluded 2905 individuals with inadequate dietary measures (less than three $24 \mathrm{~h}$ dietary records or under-reporting), leading to a final sample of 48010 individuals. Compared with excluded individuals, included individuals were more often women, aged 30-65 years, had higher educational level, higher monthly income, and were less likely to have children living in their household, more physically active, more likely to spend time on home-meal preparation, to have high cooking skills and to enjoy cooking (all $P<0 \cdot 0001$ ) (Table 2 ).

Table 3 shows adherence to nutritional guidelines, energy and food group intakes according to the importance assigned to each dish choice motive. Significant differences in diet quality were observed for all motives, although some were relatively small. The main differences were observed between individuals attaching importance to bealthy diet and to a lesser extent to specific diets compared with their respective counterparts, whereas no meaningful nutritional differences were observed for constraints, pleasure and organisation. Regarding food group intakes, individuals attaching importance to a bealthy diet and to specific diets had both higher intakes of fruits and vegetables, whereas they reported lower intakes of meat, milk and cheese and sugary products compared with their respective counterparts. These individuals were also more likely to consume whole-grain starchy foods and less likely to eat convenience foods. Individuals placing importance on a bealthy diet were also more likely to consume legumes and individuals placing importance on specific diets were less likely to consume eggs. Individuals who gave importance to organisation exhibited higher intakes of fruits. In turn, no meaningful nutritional differences were found regarding

Table 1. Explanatory factor analysis of motives for dish choices on weekdays ( $n 50915$ individuals; NutriNet-Santé study 2013) (Mean factors and standard deviations)

\begin{tabular}{|c|c|c|c|c|c|c|}
\hline $\begin{array}{l}\text { When choosing the dishes you are going to cook, how } \\
\text { important are the following criteria? }\end{array}$ & $\begin{array}{l}\text { Standardised } \\
\text { factor loading }\end{array}$ & $\begin{array}{l}\text { Internal } \\
\text { consistency }\end{array}$ & $\begin{array}{l}\text { Eigen } \\
\text { value }\end{array}$ & $\begin{array}{c}\text { Variance } \\
\text { explained (\%) }\end{array}$ & Mean & SD \\
\hline Factor 1: healthy diet & & 0.75 & $4 \cdot 82$ & $48 \cdot 3$ & 3.93 & 0.62 \\
\hline Nutritional balance of the meal & 0.87 & & & & & \\
\hline Nutritional balance of the dish & 0.81 & & & & & \\
\hline Use of seasonal products & 0.51 & & & & & \\
\hline My eating habits and/or that of my relatives & 0.40 & & & & & \\
\hline What I and/or my relatives ate during the previous days & 0.40 & & & & & \\
\hline Factor 2: constraints & & 0.68 & 1.89 & $19 \cdot 0$ & 3.77 & 0.56 \\
\hline Ingredients at my disposal & 0.61 & & & & & \\
\hline Leftovers in my refrigerator/freezer & 0.53 & & & & & \\
\hline My state of fatigue & 0.53 & & & & & \\
\hline Time available for cooking & 0.51 & & & & & \\
\hline My hunger and/or that of my relatives & 0.45 & & & & & \\
\hline My cooking skills & 0.41 & & & & & \\
\hline Factor 3: pleasure & & 0.66 & $1 \cdot 21$ & $12 \cdot 1$ & 3.39 & 0.59 \\
\hline What I and/or my relatives want to eat & 0.62 & & & & & \\
\hline Originality of the dish & 0.55 & & & & & \\
\hline My preferences and/or those of my relatives & 0.54 & & & & & \\
\hline Recipes I come across & 0.47 & & & & & \\
\hline The dish can be adapted to please all guests & 0.39 & & & & & \\
\hline Factor 4: specific diets & & 0.69 & 1.09 & $11 \cdot 0$ & $2 \cdot 80$ & 0.99 \\
\hline My health status and/or that of my relatives & 0.75 & & & & & \\
\hline My eventual diet to lose weight and/or that of my relatives & 0.64 & & & & & \\
\hline My personal convictions and/or that of my relatives & 0.47 & & & & & \\
\hline Factor 5: organisation & & 0.64 & 0.96 & $9 \cdot 6$ & 2.89 & 0.87 \\
\hline The dish can be prepared beforehand & 0.71 & & & & & \\
\hline The dish can be prepared in large quantities & 0.51 & & & & & \\
\hline What I planned to eat (meal planning) & 0.49 & & & & & \\
\hline
\end{tabular}


Table 2. Sociodemographic and lifestyle characteristics of included and excluded participants ( $n$ 48010; NutriNet-Santé study 2013)

\begin{tabular}{|c|c|c|c|}
\hline & Included (n 48010$)$ & Excluded ( $n$ 5015) & \\
\hline & $(\%)$ & $(\%)$ & $P^{*}$ \\
\hline Sex & & & $<0.0001$ \\
\hline Women & $55 \cdot 0$ & $79 \cdot 6$ & \\
\hline Men & $45 \cdot 0$ & $20 \cdot 4$ & \\
\hline Age (years) & & & $<0.0001$ \\
\hline $18-30$ & $12 \cdot 2$ & 10.5 & \\
\hline $30-50$ & $29 \cdot 3$ & $35 \cdot 9$ & \\
\hline $50-65$ & 33.9 & $35 \cdot 9$ & \\
\hline$\geq 65$ & 24.7 & $17 \cdot 7$ & \\
\hline Education & & & $<0.0001$ \\
\hline Up to secondary school & $42 \cdot 2$ & $34 \cdot 1$ & \\
\hline Some college & $25 \cdot 1$ & $30 \cdot 0$ & \\
\hline University & 28.2 & $33 \cdot 3$ & \\
\hline Missing data & 4.5 & $2 \cdot 6$ & \\
\hline Monthly income $(€ / C U) \dagger$ & & & $<0.0001$ \\
\hline$<1200$ & $16 \cdot 8$ & $14 \cdot 0$ & \\
\hline $1200-1800$ & $24 \cdot 2$ & 23.7 & \\
\hline $1800-2700$ & $22 \cdot 4$ & 24.9 & \\
\hline$\geq 2700$ & $25 \cdot 0$ & $26 \cdot 6$ & \\
\hline $\bar{M}$ issing data & $11 \cdot 7$ & $10 \cdot 8$ & \\
\hline Family status & & & $<0.0001$ \\
\hline Living with a partner, with at least one child & $23 \cdot 0$ & $25 \cdot 7$ & \\
\hline Living with a partner, without children & 53.0 & $47 \cdot 0$ & \\
\hline Living alone, with at least one child & 3.9 & $3 \cdot 8$ & \\
\hline Living alone, without children & $20 \cdot 1$ & 23.5 & \\
\hline Missing data & 0.02 & 0.02 & \\
\hline Physical activity level & & & $<0.0001$ \\
\hline Low & 10.5 & $17 \cdot 8$ & \\
\hline Moderate & $18 \cdot 2$ & $35 \cdot 3$ & \\
\hline High & $15 \cdot 2$ & $28 \cdot 3$ & \\
\hline Missing data & $56 \cdot 2$ & $18 \cdot 6$ & \\
\hline
\end{tabular}

food group intakes according to the importance attached to constraints and pleasure. Individuals placing importance on constraints were however more likely to be consumers of convenience foods whereas individuals who reported pleasure as important were less likely to be consumers of eggs, legumes, whole-grain starchy foods and convenience foods. For these models, the association of predicted probabilities and observed responses indicated percentage concordance ranging from 54.7 to $62.5 \%$ according to the food group considered. Sensitivity analyses using thresholds of 3 and 3.5 were also performed and showed similar results.

\section{Discussion}

Using a large, population-based sample, we found that attaching importance to bealthy eating and specific diets was associated with a better adherence to nutritional guidelines, higher intakes of fruits, vegetables, whole-grain starchy foods, and a lower consumption of meat, milk and cheese, sugary products and convenience foods. In turn, the importance attached to constraints, pleasure and organisation showed relatively small associations with diet quality, regarding adherence to nutritional guidelines and food intakes.

Individuals placing importance on a bealthy diet were more likely to comply with French nutritional guidelines. In particular, these individuals consumed more fruits, vegetables, starchy foods (including legumes and whole-grain starchy foods), whereas they were less likely to consume meat, dairy products and convenience foods. There is, to our knowledge, no data in the literature evaluating the association between motives during home-meal preparation and food intake. However, our results can be linked to previous data showing that an individual's concern about nutrition is positively related to the nutritional quality of the diet. In particular, several studies showed that a higher importance assigned to healthy eating was positively associated with adherence to dietary recommendations ${ }^{(41,42)}$, as well as intake of fruit and vegetables ${ }^{(43-47)}$, and fibres ${ }^{(46)}$, whereas it was negatively associated with saturated fat intake ${ }^{(46)}$. In addition, health interest has been previously described as the most significant reason for reducing meat and meat products in the $\operatorname{diet}^{(48)}$, thus supporting our results. One possible explanation to account for the reduced consumption of dairy products might be due to the ongoing debate about their possible negative impacts on health (e.g. increased risk for prostate cancer) ${ }^{(49)}$. As regards the use of convenience foods, in line with our results, a previous study investigating the motives behind different meal solutions (i.e. homemade meals, ready meals, take-out and eating out) highlighted that greater importance placed on health and wellbeing would encourage home-meal preparation, and decrease the recourse to convenience food ${ }^{(26)}$. 


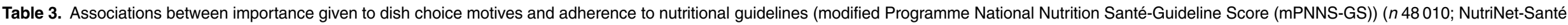
study 2013)*

(Mean values and standard deviations; odds ratios and $95 \%$ confidence intervals)

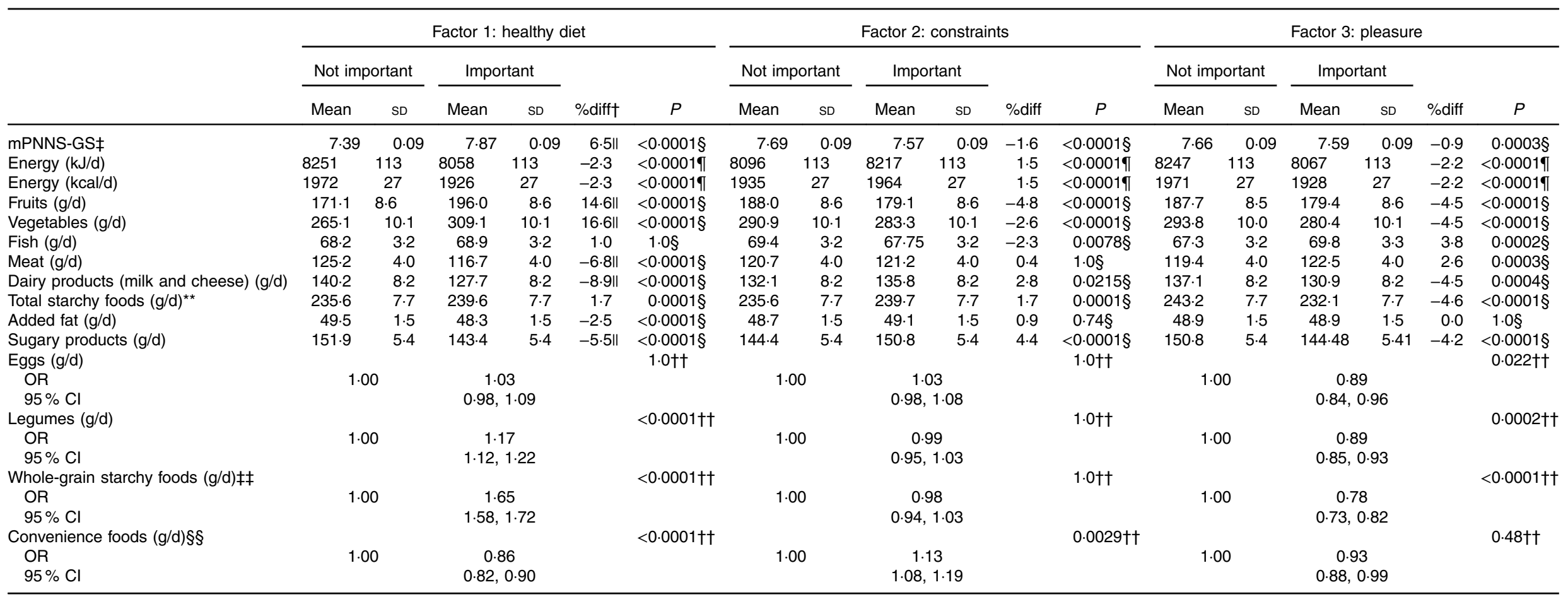


Table 3. Continued

\begin{tabular}{|c|c|c|c|c|c|c|c|c|c|c|c|c|}
\hline & \multicolumn{6}{|c|}{ Factor 4: specific diets } & \multicolumn{6}{|c|}{ Factor 5: organisation } \\
\hline & \multicolumn{2}{|c|}{ Not important } & \multicolumn{2}{|c|}{ Important } & \multirow[b]{2}{*}{ \%diff } & \multirow[b]{2}{*}{$P$} & \multicolumn{2}{|c|}{ Not important } & \multicolumn{2}{|c|}{ Important } & \multirow[b]{2}{*}{ \%diff } & \multirow[b]{2}{*}{$P$} \\
\hline & Mean & SD & Mean & SD & & & Mean & SD & Mean & SD & & \\
\hline mPNNS-GS $\ddagger$ & 7.53 & 0.09 & 7.73 & 0.09 & $2 \cdot 7$ & $<0.0001 \S$ & 7.60 & 0.09 & 7.66 & 0.09 & 0.8 & $0.031 \S$ \\
\hline Energy $(\mathrm{kJ} / \mathrm{d})$ & 8272 & 113 & 8042 & 113 & $-2 \cdot 8$ & $<0.0001 \Phi$ & 8138 & 113 & 8175 & 113 & 0.5 & 1.09 \\
\hline Energy $(\mathrm{kcal} / \mathrm{d})$ & 1977 & 27 & 1922 & 27 & $-2 \cdot 8$ & $<0.0001 \pi$ & 1945 & 27 & 1954 & 27 & 0.5 & $1.0 \pi$ \\
\hline Fruits $(\mathrm{g} / \mathrm{d})$ & 178.4 & 8.5 & $188 \cdot 7$ & 8.6 & $5 \cdot 8 \|$ & $<0.0001 \S$ & 178.9 & 8.5 & $188 \cdot 2$ & 8.6 & $5 \cdot 2 \|$ & $<0.0001 \S$ \\
\hline Vegetables $(\mathrm{g} / \mathrm{d})$ & 279.8 & $10 \cdot 0$ & 294.3 & $10 \cdot 1$ & $5 \cdot 2 \|$ & $<0.0001 \S$ & $283 \cdot 2$ & $10 \cdot 0$ & 291.0 & $10 \cdot 2$ & $2 \cdot 8$ & $<0.0001 \S$ \\
\hline Fish (g/d) & $69 \cdot 1$ & $3 \cdot 2$ & $68 \cdot 1$ & $3 \cdot 3$ & -1.5 & $1.0 \S$ & $68 \cdot 8$ & $3 \cdot 2$ & $68 \cdot 3$ & 3.3 & -0.7 & $1.0 \S$ \\
\hline Meat $(\mathrm{g} / \mathrm{d})$ & $125 \cdot 3$ & 4.0 & $116 \cdot 6$ & $4 \cdot 1$ & $-7.0 \|$ & $<0.0001 \S$ & 118.9 & 4.0 & 123.0 & $4 \cdot 1$ & 3.4 & $<0.0001 \S$ \\
\hline Dairy products (milk and cheese) $(\mathrm{g} / \mathrm{d})$ & 138 & $8 \cdot 2$ & 129.7 & $8 \cdot 2$ & $-6 \cdot 1 \|$ & $<0.0001 \S$ & $130 \cdot 8$ & $8 \cdot 1$ & $137 \cdot 1$ & $8 \cdot 3$ & 4.8 & $0.0015 \S$ \\
\hline Total starchy foods $(\mathrm{g} / \mathrm{d})^{\star *}$ & 236.7 & $7 \cdot 7$ & 238.6 & $7 \cdot 7$ & 0.8 & $0.18 \S$ & 238.0 & $7 \cdot 6$ & $237 \cdot 2$ & 7.7 & -0.3 & $0.60 \S$ \\
\hline Added fat $(\mathrm{g} / \mathrm{d})$ & $50 \cdot 0$ & 1.5 & 47.9 & 1.5 & $-4 \cdot 2$ & $<0.0001 \S$ & 48.9 & 1.5 & $49 \cdot 0$ & 1.5 & 0.3 & $1.0 \S$ \\
\hline Sugary products $(g / d)$ & $151 \cdot 2$ & 5.4 & $144 \cdot 1$ & 5.4 & -4.7 & $<0.0001 \S$ & 147.5 & 5.4 & 147.8 & 5.4 & 0.2 & $1.0 \S$ \\
\hline Eggs (g/d) & & & & & & $<0.0001 \dagger \dagger$ & & & & & & $1.0 \dagger \dagger$ \\
\hline $\begin{array}{l}\mathrm{OR} \\
95 \% \mathrm{Cl}\end{array}$ & \multicolumn{2}{|c|}{1.00} & \multicolumn{2}{|c|}{$\begin{array}{c}0.82 \\
0.77,0.88\end{array}$} & & & \multicolumn{2}{|c|}{1.00} & \multicolumn{2}{|c|}{$\begin{array}{c}0.99 \\
0.92,1.06\end{array}$} & & \\
\hline Legumes (g/d) & \multirow{2}{*}{\multicolumn{2}{|c|}{1.00}} & & & & $0.48+\dagger$ & \multirow{2}{*}{\multicolumn{2}{|c|}{1.00}} & & & & $1.0+\dagger$ \\
\hline $\begin{array}{l}\text { OR } \\
95 \% \mathrm{Cl}\end{array}$ & & & \multicolumn{2}{|c|}{$\begin{array}{c}0.94 \\
0.89,0.99\end{array}$} & & & & & \multicolumn{2}{|c|}{$\begin{array}{c}1.02 \\
0.96,1.08\end{array}$} & & \\
\hline Whole-grain starchy foods $(\mathrm{g} / \mathrm{d}) \ddagger \ddagger$ & \multirow{2}{*}{\multicolumn{2}{|c|}{1.00}} & \multirow{2}{*}{\multicolumn{2}{|c|}{$\begin{array}{c}1.29 \\
1.22,1.36\end{array}$}} & & $<0.0001 \dagger \dagger$ & \multirow{2}{*}{\multicolumn{2}{|c|}{1.00}} & \multirow{2}{*}{\multicolumn{2}{|c|}{$\begin{array}{c}0.90 \\
0.85,0.95\end{array}$}} & & $0.01+\dagger$ \\
\hline $\begin{array}{l}\text { OR } \\
95 \% \mathrm{Cl}\end{array}$ & & & & & & & & & & & & \\
\hline Convenience foods $(\mathrm{g} / \mathrm{d}) \S \S$ & \multirow{2}{*}{\multicolumn{2}{|c|}{1.00}} & \multirow{2}{*}{\multicolumn{2}{|c|}{$\begin{array}{c}0.78 \\
0.73,0.83\end{array}$}} & & $<0.0001 \dagger \dagger$ & \multirow{2}{*}{\multicolumn{2}{|c|}{1.00}} & \multirow{2}{*}{\multicolumn{2}{|c|}{$\begin{array}{c}0.99 \\
0.92,1.06\end{array}$}} & & $1.0+\dagger$ \\
\hline $\begin{array}{l}\text { OR } \\
95 \% \mathrm{Cl}\end{array}$ & & & & & & & & & & & & \\
\hline
\end{tabular}

* Importance placed on dish choice motives was defined by calculating the mean rating (five-point Likert scale) of items loading in each factor: important (mean score $\geq 4$ ), not important (mean score <4).

† Percentage of difference in dietary intakes between individuals attaching importance $v$. those who do not, all such data.

$\ddagger$ mPNN-GS: adherence to nutritional guidelines score.

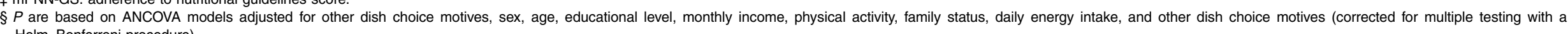
Molm-Bonferroni procedure)

Meaningful nutritional differences, that is, over the threshold of $5 \%$.

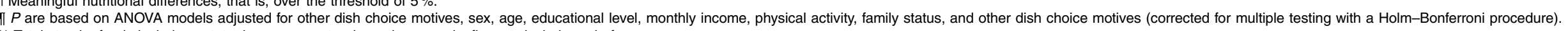
* Tolal starchy foods includes potato, legumes, pasta, rice, other cereals, flour and whole-grain forms.

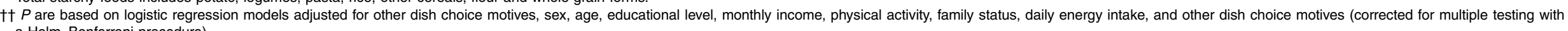
a Holm-Bonferroni procedure).

(2) pasta, rice, other cereals, and flour.

$\S \S$ Convenience food includes pizzas, burgers, salted pies, salted cakes, sandwich, fried meal. 
Individuals attributing importance to a specific diet when choosing their dishes exhibited relatively better adherence to nutritional guidelines compared with their respective counterparts, although the differences were lower than those observed for the bealthy diet motive. They also had higher intakes of fruits, vegetables and whole-grain starchy foods, whereas they reported lower intakes of meat, milk, cheese, eggs and convenience foods. Individuals could assign importance to this motive for various reasons such as diabetes, food intolerance or allergy, diet to lose weight, vegetarianism or religion. Most of these reasons are expected to lead individuals to adopt a healthier diet. However, given the differences in dietary practices across specific diets, results on food group intakes should be carefully interpreted. In the literature, health status ${ }^{(50,51)}$ and weight preoccupation ${ }^{(50,51)}$ have both been described as important motivations to eat healthily. In our study, the higher consumption of fruit and vegetables in individuals placing importance on a specific diet is consistent with many weightloss diets ${ }^{(52)}$, as well as vegetarian diets ${ }^{(53)}$ and might be explained by their beneficial effects on health ${ }^{(54)}$ in individuals dieting for health reasons. The lower consumption of meat is also consistent with vegetarian ${ }^{(53)}$ as well as Mediterranean dietary patterns that could be followed for weight-loss ${ }^{(52)}$ or health reasons ${ }^{(55)}$. Lower intakes of dairy products have been previously described in subjects with the metabolic syndrome ${ }^{(56)}$ but can be also attributed to vegan and lactose-free diets. The higher consumption of whole-grain starchy foods is in line with vegetarian dietary patterns ${ }^{(57)}$. The lower intake of convenience food might be due to the unhealthy perception of such products ${ }^{(26)}$, potentially exacerbated in individuals dieting to lose weight or for health reasons, and to concerns about their naturalness, more specifically among vegetarians ${ }^{(13)}$.

Although people who attribute high importance to bealthy diet or to a specific diet have a healthier diet, other motives may influence dish choices, thus potentially limiting the importance of healthy eating criteria. To support individuals taking into account such criteria, previous findings have emphasised the potential interest in giving people everyday practicalities to achieve a healthy diet during home preparation - that is, increasing food literacy that includes knowledge, skills and behaviours ${ }^{(58)}$.

In our study, giving importance to constraints, pleasure or organisation was not associated or little associated with meaningful differences in terms of diet quality. Conversely, the literature reported significant associations between motivations behind food choices and dietary intake. Time spent on food preparation and cooking skills, which are often related to cooking constraints, have been previously associated with higher fruit and vegetables intakes ${ }^{(7,11)}$. Regarding pleasure, research on overeating and self-regulation has associated eating pleasure with short-term visceral impulses, potentially leading to high energy intake ${ }^{(59)}$. Finally, meal planning has been associated with a higher consumption of fruits ${ }^{(60,61)}$. These discrepancies might be explained by several hypotheses. First, the fact that individuals considered the motives as important might induce different behaviours. For example, constraints could have a negative impact on dietary quality but it can also lead individuals to plan their meals in advance, which has been associated with a better diet quality ${ }^{(60)}$. Second, even if one motive is important, the balance with other motives may not induce a significant impact on diet quality. In particular, as our sample is highly interested in nutritional issues, they may attempt to conciliate pleasure and constraints with bealthy eating or specific diets. Finally, it is also possible that individuals take into account, in an implicit way, these motives and therefore did not rate them as important.

Helping individuals to conciliate the different motives influencing their dish choice and encouraging them to confer importance to healthy eating appears to be a potential way to improve diet quality. Further, our results, considered together with the relationships established between cooking practices and dish choice motives ${ }^{(27)}$ on one hand and cooking practices and diet quality on the other hand, suggest the interest in investigating how cooking practices potentially mediate the association between dish choice motives and diet quality. Such studies would provide more concrete applications in terms of public health policies.

\section{Strengths and limitations}

To our knowledge, this study is the first to provide a global approach on how dish choice motives are associated with diet quality. A major strength of our study was the use of at least three $24 \mathrm{~h}$ recalls, which allowed an accurate estimate of the dietary intakes ${ }^{(62)}$. The web-based tool used in the NutriNet-Santé study showed high agreement with the reference method - that is, interview with a dietitian ${ }^{(63)}$, and a good validity against biomarkers to assess diet quality ${ }^{(64,65)}$. Dietary quality was assessed by different methods, including an $a$ priori score evaluating adherence to nutritional guidelines and food group consumptions, in order to more precisely access eating habits. Another important strength of our study was the large sample size, including subjects with different sociodemographic and cooking practice characteristics.

The main limitation of our study is the use of a cross-sectional design, which does not allow drawing conclusion on causality. The issue of the generalisability of our results should also be raised as participants are volunteers in a long-term cohort and therefore are likely to be more health conscious and to have a higher dietary quality compared with the general French population. Furthermore, the profile of individuals included in the study compared with those excluded (more often women, aged 30-65 years, higher educational level, higher income, less likely to have children living in their household) may have exacerbated this characteristic. Given that participants were particularly interested in nutritional issues, desirability bias might have led to an over-estimation of the importance attributed to healthy eating criteria. In addition, our results have been potentially affected by common bias of auto-administered questionnaires, such as desirability bias. However, these may have been partially limited by the web-design which improves the feeling of anonymity ${ }^{(66)}$. A potential acquiescence bias should also be considered, especially because our questionnaire included a large number of items and the Likert scale included a middle point. The fact that item presentation was not randomised across participants might also have led to misreporting because of primacy effect 
(i.e. the fact that participant responses are influenced by the data presented earlier) or because of lassitude at the end of the questionnaire. Another potential bias lies in the difficulty of participants to make an overall evaluation of their food choices as they might differ according to the context (e.g. type of meal, type of commensals, meal occasion). We attempted to partially limit this bias by evaluating separately weekdays and weekends. The use of a seven- or nine-point instead of a five-point Likert scale may have allowed individuals to more precisely estimate the level of importance they attribute to each criterion. However, this would increase the cognitive workload and completion time of the questionnaire, which may have discouraged some participants to finish it. Finally, the threshold of $5 \%$ has been defined as a meaningful difference of diet quality; however, it is possible that smaller differences may also have nutritional implications at the population level.

\section{Conclusion}

In conclusion, this study highlighted that attaching importance on bealthy diet and to a lesser extent specific diets is associated with better adherence to nutritional guidelines, and more specifically higher intakes of fruits, vegetables, whole-grain starchy foods, and lower intakes of meat, milk, cheese and convenience foods. Higher fruit intake was also found in individuals considering organisation as important. In turn, no meaningful nutritional differences were observed when importance was placed on constraints and pleasure. These findings suggest that enabling individuals to prioritise a healthy diet during homemeal preparation might potentially encourage better dietary quality. For this purpose, it seems important to develop the ability of individuals to cook dishes that are not only good for health but also pleasurable, under the specific constraints of individuals. Thus, cooking classes or specific apps providing adapted recipes appear as interesting strategies. Further prospective studies are needed to explore the causal relationships between dish choice motives and diet quality, and how cooking practices potentially mediate this relationship.

\section{Acknowledgements}

The authors thank all the scientists, dietitians, technicians and assistants who helped carry out the NutriNet-Santé study. The authors especially thank Younes Esseddik, Yasmina Chelghoum, Mohand Ait Oufella, Paul Flanzy and Thi Hong Van Duong, computer scientists; Veronique Gourlet, Charlie Menard, Fabien Szabo, Nathalie Arnault, Laurent Bourhis and Stephen Besseau, statisticians; and the dietitians. The authors are grateful to volunteers from the NutriNet-Santé study.

The NutriNet-Santé Study is supported by the French Ministry of Health, the French Institute for Public Health Surveillance, the French National Institute for Health and Medical Research, the French National Institute for Agricultural Research, the Medical Research Foundation, the National Conservatory for Arts and Crafts, the National Institute for Prevention and Health Education and the University of Paris 13 . This study was supported by the Open Food System project. The Open Food
System is a research project supported by Vitagora, Cap Digital, Imaginove, Aquimer, Microtechnique and Agrimip, financed by the French State and the Franche-Comté Region as part of The Investments for the Future Programme managed by Bpifrance.

P. D.: conducted the literature review, drafted the manuscript and performed analyses; C. M., B. A., P. F., S. H. and S. P.: were involved in the interpretation of results and critically reviewed the manuscript; and S. H. and S. P.: were responsible for the development of the design and the protocol of the study. All authors read and approved the final manuscript.

The authors declare that there are no conflicts of interest.

\section{Supplementary material}

For supplementary material/s referred to in this article, please visit https://doi.org/10.1017/S0007114517000666

\section{References}

1. Short F (2003) Domestic cooking practices and cooking skills: findings from an English study. Food Serv Technol 3, 177-185.

2. Mancino L \& Newman C (2007) Who Has Time To Cook? How Family Resources Influence Food Preparation? Washington, DC: US Department of Agriculture, Economic Research Service.

3. Smith LP, Ng SW \& Popkin BM (2013) Trends in US home food preparation and consumption: analysis of national nutrition surveys and time use studies from 1965-1966 to 2007-2008. Nutr J 12, 45.

4. Adams J, Goffe L, Brown T, et al. (2015) Frequency and sociodemographic correlates of eating meals out and take-away meals at home: cross-sectional analysis of the UK national diet and nutrition survey, waves 1-4 (2008-12). Int J Behav Nutr Phys Act 12, 51.

5. Guthrie JF, Lin BH \& Frazao E (2002) Role of food prepared away from home in the American diet, 1977-78 versus 1994-96: changes and consequences. J Nutr Educ Behav 34, $140-150$.

6. Kant AK \& Graubard BI (2004) Eating out in America, 1987-2000: trends and nutritional correlates. Prev Med 38, 243-249.

7. Hartmann C, Dohle S \& Siegrist M (2013) Importance of cooking skills for balanced food choices. Appetite $\mathbf{6 5}$, 125-131.

8. Larson NI, Perry CL, Story M, et al. (2006) Food preparation by young adults is associated with better diet quality. $J$ Am Diet Assoc 106, 2001-2007.

9. Larson NI, Story M, Eisenberg ME, et al. (2006) Food preparation and purchasing roles among adolescents: associations with sociodemographic characteristics and diet quality. J Am Diet Assoc 106, 211-218.

10. Laska MN, Larson NI, Neumark-Sztainer D, et al. (2012) Does involvement in food preparation track from adolescence to young adulthood and is it associated with better dietary quality? Findings from a 10-year longitudinal study. Public Health Nutr 15, 1150-1158.

11. Monsivais P, Aggarwal A \& Drewnowski A (2014) Time spent on home food preparation and indicators of healthy eating. Am J Prev Med 47, 796-802.

12. Wrieden WL, Anderson AS, Longbottom PJ, et al. (2007) The impact of a community-based food skills intervention on cooking confidence, food preparation methods and dietary choices - an exploratory trial. Public Health Nutr 10, 203-211. 
13. Brunner TA, van der Horst K \& Siegrist M (2010) Convenience food products. Drivers for consumption. Appetite 55, 498-506.

14. van der Horst K, Brunner TA \& Siegrist M (2011) Ready-meal consumption: associations with weight status and cooking skills. Public Health Nutr 14, 239-245.

15. Black AE (2000) Critical evaluation of energy intake using the Goldberg cut-off for energy intake:basal metabolic rate. A practical guide to its calculation, use and limitations. Int J Obes Relat Metab Disord 24, 1119-1130.

16. Blake CE, Devine CM, Wethington E, et al. (2009) Employed parents' satisfaction with food-choice coping strategies. Influence of gender and structure. Appetite 52, 711-719.

17. Blake CE, Wethington E, Farrell TJ, et al. (2011) Behavioral contexts, food-choice coping strategies, and dietary quality of a multiethnic sample of employed parents. J Am Diet Assoc 111, 401-407.

18. Jabs J \& Devine CM (2006) Time scarcity and food choices: an overview. Appetite 47, 196-204.

19. Jabs J, Devine CM, Bisogni CA, et al. (2007) Trying to find the quickest way: employed mothers' constructions of time for food. J Nutr Educ Behav 39, 18-25.

20. Eertmans A, Victoir A, Vansant G, et al. (2006) The Food Choice Questionnaire: factorial invariant over western urban populations? Food Qual Prefer 16, 714-726.

21. Januszewska R, Pieniak Z \& Verbeke W (2011) Food choice questionnaire revisited in four countries. Does it still measure the same? Appetite 57, 94-98.

22. Pieniak Z, Verbeke W, Vanhonacker F, et al. (2009) Association between traditional food consumption and motives for food choice in six European countries. Appetite 53, 101-108.

23. Prescott J, Young O, O'Neill L, et al. (2002) Motives for food choice: a comparison of consumers from Japan, Taiwan, Malaysia and New Zealand. Food Qual Prefer 13, 489-495.

24. Steptoe A, Pollard TM \& Wardle J (1995) Development of a measure of the motives underlying the selection of food: the food choice questionnaire. Appetite 25, 267-284.

25. Allès B, Péneau S, Kesse-Guyot E, et al. (2015) Association between sustainable food choice motives during purchasing and dietary patterns in French adults. Proc Nutr Soc 74 (OCE5) E353.

26. Costa AIA, Schoolmeester D, Dekker M, et al. (2007) To cook or not to cook: a means-end study of motives for choice of meal solutions. Food Qual Prefer 18, 77-88.

27. Ducrot P, Mejean C, Alles B, et al. (2015) Motives for dish choices during home meal preparation: results from a large sample of the NutriNet-Sante study. Int J Behav Nutr Phys Act 12, 120.

28. Hercberg S, Castetbon K, Czernichow S, et al. (2010) The Nutrinet-Sante Study: a web-based prospective study on the relationship between nutrition and health and determinants of dietary patterns and nutritional status. BMC Public Health 10, 242

29. Institut National de la Statistique et des Etudes Economiques (2014) Consumption unit definition. https://www.insee.fr/en/ metadonnees/definition/c1802

30. Hercberg S, Chat-Yung S \& Chaulia M (2008) The French National Nutrition and Health Program: 2001-2006-2010. Int J Public Health 53, 68-77.

31. Le Moullec N, Dheeger M, Preziosi P, et al. (1996) Validation du manuel photos utilisé pour l'enquête alimentaire de l'étude SU.VI.MAX (Validation of photographic document used to estimate the amounts of foods eaten by subjects in the SU.VI. MAX study). Cah Nutr Diet 31, 158-164.

32. NutriNet-Santé Coordination (2013) Table de composition des aliments - Etude NutriNet-Santé. Paris: Economica.

33. Estaquio C, Kesse-Guyot E, Deschamps V, et al. (2009) Adherence to the French Programme National Nutrition Sante
Guideline Score is associated with better nutrient intake and nutritional status. J Am Diet Assoc 109, 1031-1041.

34. Hercberg S, Chat-Yung S \& Chaulia M (2008) The French National Nutrition and Health Program: 2001-2006-2010. Int J Public Health 53, 68-77.

35. Martin A (2001) Apports nutritionnels conseillés pour la population française. Paris: Lavoisier/AFSSA.

36. Flora DB, Labrish C \& Chalmers RP (2012) Old and new ideas for data screening and assumption testing for exploratory and confirmatory factor analysis. Front Psychol 3, 55.

37. Hatcher L (1994) A Step-by-Step Approach to Using the SAS System for Factor Analysis and Structural Equation Modeling. Cary, NC: SAS Institute Inc.

38. Catell RB (1966) The scree test for the number of factors. Multivariate Behav Res 1, 245-276.

39. Hair JF, Black WC, Babin BJ, et al. (2006) Multivariate Data Analysis, 6th ed. Upper Saddle River, NJ: Pearson Prentice Hall.

40. Berglund PA (2010) An Introduction to Multiple Imputation of Complex Sample Data using SAS ${ }^{\circledR}$ v9.2. Cary, NC: SAS Institute Inc.

41. Alkerwi A, Sauvageot N, Malan L, et al. (2015) Association between nutritional awareness and diet quality: evidence from the observation of cardiovascular risk factors in Luxembourg (ORISCAV-LUX) study. Nutrients 7, 2823-2838.

42. Biltoft-Jensen A, Groth MV, Matthiessen J, et al. (2009) Diet quality: associations with health messages included in the Danish Dietary Guidelines 2005, personal attitudes and social factors. Public Health Nutr 12, 1165-1173.

43. Hearty AP, McCarthy SN, Kearney JM, et al. (2007) Relationship between attitudes towards healthy eating and dietary behaviour, lifestyle and demographic factors in a representative sample of Irish adults. Appetite $\mathbf{4 8}, 1-11$.

44. Pollard J, Greenwood D, Kirk S, et al. (2001) Lifestyle factors affecting fruit and vegetable consumption in the UK Women's Cohort Study. Appetite 37, 71-79.

45. Pollard J, Kirk SF \& Cade JE (2002) Factors affecting food choice in relation to fruit and vegetable intake: a review. Nutr Res Rev 15, 373-387.

46. Talvia S, Rasanen L, Lagstrom H, et al. (2011) Parental eating attitudes and indicators of healthy eating in a longitudinal randomized dietary intervention trial (the STRIP study). Public Health Nutr 14, 2065-2073.

47. Dittus KL, Hillers VN \& Beerman KA (1995) Benefits and barriers to fruit and vegetable intake: relationship between attitudes and consumption. J Nutr Educ 27, 120-126.

48. Holt GC (2016) 'Ecological eating', food ideology and food choice. Bradford: Food Policy Research Unit, Department of Biomedical Sciences, University of Bradford.

49. Lampe JW (2011) Dairy products and cancer. J Am Coll Nutr 30, $464 \mathrm{~S}-470 \mathrm{~S}$.

50. Dijkstra SC, Neter JE, Brouwer IA, et al. (2014) Motivations to eat healthily in older Dutch adults - a cross sectional study. Int J Behav Nutr Phys Act 11, 141.

51. Satia JA, Kristal AR, Curry S, et al. (2001) Motivations for healthful dietary change. Public Health Nutr 4, 953-959.

52. Shai I, Schwarzfuchs D, Henkin Y, et al. (2008) Weight loss with a low-carbohydrate, Mediterranean, or low-fat diet. $N$ Engl J Med 359, 229-241.

53. Haddad EH \& Tanzman JS (2003) What do vegetarians in the United States eat? Am J Clin Nutr 78, 626S-632S.

54. Wang X, Ouyang Y, Liu J, et al. (2014) Fruit and vegetable consumption and mortality from all causes, cardiovascular disease, and cancer: systematic review and dose-response meta-analysis of prospective cohort studies. BMJ $\mathbf{3 4 9}$, g4490. 
55. Stradling C, Hamid M, Taheri S, et al. (2014) A review of dietary influences on cardiovascular health: part 2: dietary patterns. Cardiovasc Hematol Disord Drug Targets 14, 50-63.

56. Mesquita de CC, Dias MD, Haas PC, et al. (2015) Nutritional adequacy in subjects with metabolic syndrome. Nutr Hosp $\mathbf{3 1}$, $1147-1153$.

57. Orlich MJ, Jaceldo-Siegl K, Sabate J, et al. (2014) Patterns of food consumption among vegetarians and non-vegetarians. Br J Nutr 112, 1644-1653.

58. Vidgen HA \& Gallegos D (2014) Defining food literacy and its components. Appetite 76, 50-59.

59. Loewenstein G (1996) Out of control: visceral influences on behavior. Organ Behav Hum Decis Process 65, 272-292.

60. Crawford D, Ball K, Mishra G, et al. (2007) Which foodrelated behaviours are associated with healthier intakes of fruits and vegetables among women? Public Health Nutr 10, 256-265.

61. Neumark-Sztainer D, MacLehose R, Loth K, et al. (2014) What's for dinner? Types of food served at family dinner differ across parent and family characteristics. Public Health Nutr 17, $145-155$.

62. Ma Y, Olendzki BC, Pagoto SL, et al. (2009) Number of 24-hour diet recalls needed to estimate energy intake. Ann Epidemiol 19, 553-559.

63. Touvier M, Kesse-Guyot E, Mejean C, et al. (2011) Comparison between an interactive web-based self-administered $24 \mathrm{~h}$ dietary record and an interview by a dietitian for large-scale epidemiological studies. Br J Nutr 105, 1055-1064.

64. Lassale C, Castetbon K, Laporte F, et al. (2015) Validation of a web-based, self-administered, non-consecutive-day dietary record tool against urinary biomarkers. Br J Nutr 113, 953-962.

65. Lassale C, Castetbon K, Laporte F, et al. (2016) Correlations between fruit, vegetables, fish, vitamins, and fatty acids estimated by web-based nonconsecutive dietary records and respective biomarkers of nutritional status. J Acad Nutr Diet 116, 427-438.

66. Joinson A (1999) Social desirability, anonymity, and Internetbased questionnaires. Behav Res Methods Instrum Comput 31, 433-438. 